\title{
Measurement of Thermal Conductivity along the Radial Direction in a Vertical Cylindrical Packed Bed
}

\author{
Swaren Bedarkar, ${ }^{1}$ Nurni Neelakantan Viswanathan, ${ }^{2}$ and Nidambur Bharatha Ballal ${ }^{2}$ \\ ${ }^{1}$ Electrotherm (India) Limited, Ahmedabad 382115, India \\ ${ }^{2}$ Centre of Excellence in Steel Technology and Department of Metallurgical Engineering \& Materials Science, \\ Indian Institute of Technology Bombay, Mumbai 400076, India
}

Correspondence should be addressed to Swaren Bedarkar; swarenbedarkar@gmail.com

Received 9 September 2014; Revised 12 January 2015; Accepted 13 January 2015

Academic Editor: Franco Berruti

Copyright ( 2015 Swaren Bedarkar et al. This is an open access article distributed under the Creative Commons Attribution License, which permits unrestricted use, distribution, and reproduction in any medium, provided the original work is properly cited.

Heat transfer in packed beds and their thermal response have been of great interest for scientists and engineers for the last several years, since they play a crucial role in determining design and operation of reactors. Heat transfer of a packed bed is characterised through lumped parameter, namely, effective thermal conductivity. In the present studies, experiments were performed to investigate the thermal conductivity of a packed bed in radial direction. The packed bed was formed using iron ore particles. To determine the effective thermal conductivity a new transient methodology is proposed. The results obtained were compared with the models proposed by ZBS and Kunii and Smith.

\section{Introduction}

Packed beds have extensive applications in industrial thermal systems: metallurgical process units, chemical reactors, thermal storage units, heat exchangers, combustors, and so forth. Heat transfer in packed beds and their thermal response have been of great interest for scientists and engineers. In this context, authors have been involved in development of a process in which the sensible heat of off-gas is being utilised to produce directly reduced iron from a packed bed of iron ore fines and coal fines. The heat is being transferred indirectly to the bed via reactor wall. Since the reduction of iron ore with coal is highly endothermic, the production rate of such a reactor will be primarily controlled by the amount of heat that can be transferred through the reactor wall and subsequently through the packed bed itself. In view of this, study of heat transfer from the reactor wall to the particle bed and that through the bed itself gains considerable relevance.

Yagi and Kunii [1] in their classical paper discuss all the possible mechanisms that occur during heat transfer through packed bed. It involves mechanisms such as thermal conduction through solids, heat transfer through the contact surface area, radiant heat transfer between surfaces of neighbouring particles and beyond through voids, and heat transfer through convection and mixing of fluid.

Yagi and Kunii [1] also showed that, in packed beds with no imposed fluid flow, significant portion of the heat flows through the fluid film near the contact point of two particles. In general, heat transfer through packed beds has been characterized by an effective thermal conductivity in the bulk of the bed and a heat transfer coefficient or an effective thermal conductivity at the wall. Subsequently, researchers have carried out experiments exploring variation of void fraction near the packed bed container wall [2-4], variation of thermal conductivity due the effect of radiation $[5,6]$, variation of transport properties within a bed under moving and stagnant fluid conditions [7], and so forth. Some of the studies are also being made with radial [8-16] and axial [1, 1724] heating.

The following salient points are deduced from these studies.

(1) The variation in effective thermal conductivity and heat transfer coefficient reported by various researchers goes as high as $100 \%$. Often these variations have been attributed to inherent nature of packed bed heat transfer 
(2) A relatively less number of experiments have been reported at higher temperatures where radiation phenomena can contribute significantly to the heat transfer. It is important to note that various metallurgical processes such as extraction, melting, and heat treatment are carried out at higher temperatures where radiation plays a significant role.

(3) These studies showed difference in heat transfer characteristics along vertical (gravitational) and horizontal directions. These variations can be attributed to differences in convective flows of fluid phase in the voids as well as in contact resistances arising out of bed weight along the vertical and horizontal directions.

Large varieties of methods have been used to measure the thermal conductivity of packed beds. Tsotsas and Martin [25] classified the methods to determine thermal conductivity of packed beds as steady state and transient methods $[8,10,13$, $16,26]$, radial and axial methods [8-24], and absolute and comparative methods $[7,27]$. In steady state methods, the required boundary conditions are imposed and temperature profile within the bed is allowed to come to the steady state. Heat flux is measured and thermal conductivity of the bed is obtained by solution of Fourier or Laplace equation. In transient methods, thermal response of the bed is recorded by giving a pulse input in the form of temperature change or heat flux change. The bed conductivity is obtained by fitting the solution of Fourier equation to the measured temperature-time curve. In absolute methods, the bed conductivity is calculated from experimental results without any additional information. In comparative methods, the heat transfer in the packed bed is in series with that through a material with known conductivity. The bed conductivity is obtained by using ratios of temperature gradients within the materials.

In the present work, a new transient experimental methodology is proposed. It should be noted that thermal conductivity along the radial direction in a cylindrical bed can only be determined using transient experiments, unless the bed is annular and a sink for heat is provided [19]. Heat transfer measurements in packed beds generally show large scatter in data. Many researchers [21, 28-30] have explained this scatter as various possibilities of errors during the experiments of heat transfer in a packed bed. Authors opine that, in addition to the inherent uncertainties involved in packed bed experiments, possibilities also exist that some additional factors such as the stress distribution within the bed due its own weight as well as external load and the heat flow in the gravitational direction or in the opposite direction (changes in free convective contribution) also need to be considered. In this regard, authors have conducted some interesting experiments and those results will be communicated in their future correspondence.

Many metallurgical processes involving packed beds operate at high temperatures, that is, greater than $300^{\circ} \mathrm{C}$, wherein radiative contribution to the overall heat transfer plays an important role. However, conducting experiments at higher temperatures is more difficult than that at lower temperatures and therefore a relatively less number of experiments have been reported at higher temperatures.

In this work, heat transfer characteristics of the bed are studied at higher temperature with $1 \mathrm{D}$ radial heating of a bed of iron ore particles. In these experiments, no heat sink is used. Temperature profile inside the bed has been obtained by inserting thermocouples at various radial positions. In order to determine the thermal conductivity one needs the rate of heat input and the temperature profile. In the present methodology, the heat input to the packed bed is determined from the transient temperature inside the bed and not from the electrical power supplied to the furnace. Effective thermal conductivity of the bed is determined using the temperature profiles obtained from the experiments. The values of the conductivity are compared with the two widely used models by Kunii and Smith [31] and Schlunder and coworkers [32, 33]. Authors have conducted experiments in both directions, that is, axial and radial. Experiments in both directions showed interesting facts, which will be communicated later. In the present work, discussion has been made only for the experiments in radial direction.

\section{Experimental Setup and Procedure}

Figure 1 depicts the experimental setup for the study of radial heat transfer under transient conditions with stagnant fluid. Experiments were carried out for the bed heights of $200 \mathrm{~mm}$ and $300 \mathrm{~mm}$. The bed is formed with iron ore particles with the average size of $4.3 \mathrm{~mm}$. As shown in Figure 1(a), a cylindrical electrical resistance furnace was designed and fabricated. In order to ensure a sufficiently long hot zone wherein the temperature is uniform, three independently controlled electrical heating coils are placed, one at the center and the other two on each end of the furnace. By adjusting the heat input to the three segments independently one can achieve a large constant temperature zone. A thin wall cylinder of stainless steel 316L containing the packed bed is inserted vertically within the furnace. The packed bed is placed almost entirely within the constant temperature zone. All the temperature measurements are done in the middle section of the packed bed on a horizontal plane. Thermocouples are placed along a diameter of the packed bed. Temperature in the vicinity of any particle and within it has been verified to be within experimental error of $\pm 0.1 \%$.

Cylinder wall temperatures are obtained by embedding thermocouples into the wall, by first drilling a small blind hole and then closing it after inserting the thermocouple tip. This is to ensure good contact and, specifically, to avoid direct radiation from the furnace. To avoid the fin effect, this thermocouple is led along the wall for some distance before being taken out. Similarly the thermocouples measuring bed temperatures are led axially, since axial variation of temperature is expected to be small due to the large constant temperature zone. To ensure proper positioning of the thermocouple tips, the wires coming out through the bottom flange are weighed down so that the wire remains taut within the bed. Figure 1(b) depicts the thermocouple positions and the respective distances. Instrumentation for the 


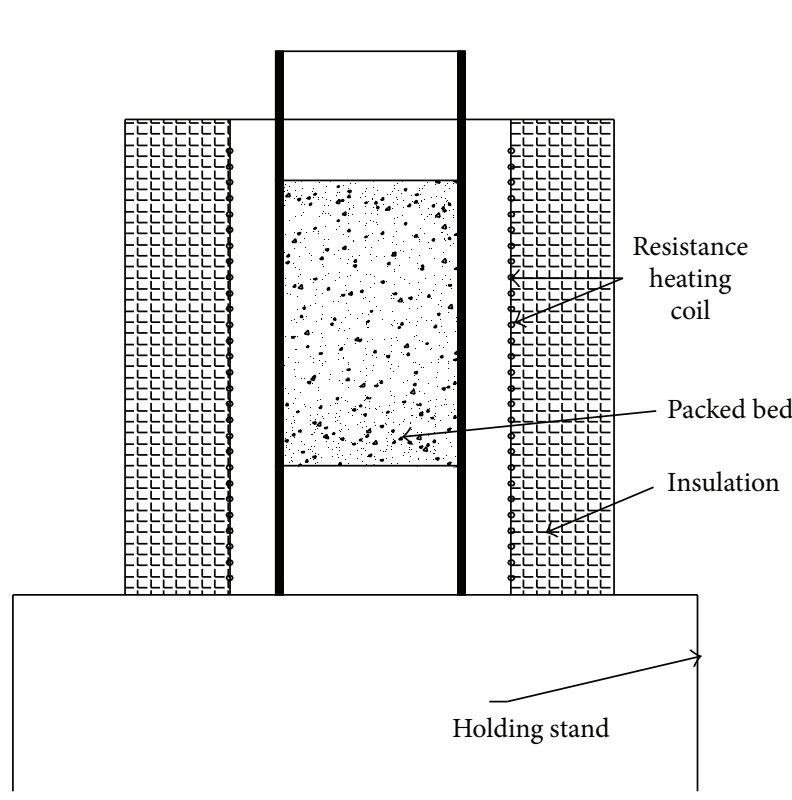

(a)

Height of the stainless steel pipe inside the heater

ID of stainless steel pipe

Wall thickness

Diameter of heating coil

Thickness of furnace insulation

Distance between various thermocouples (TC)

$\begin{array}{ll}\text { Numbers 1-3 } & 2.5 \mathrm{~mm} \\ \text { Numbers 4-5 } & 14 \mathrm{~mm} \\ \text { Numbers 6-7 } & 16 \mathrm{~mm} \\ \text { Numbers 8-9 } & 15 \mathrm{~mm}\end{array}$
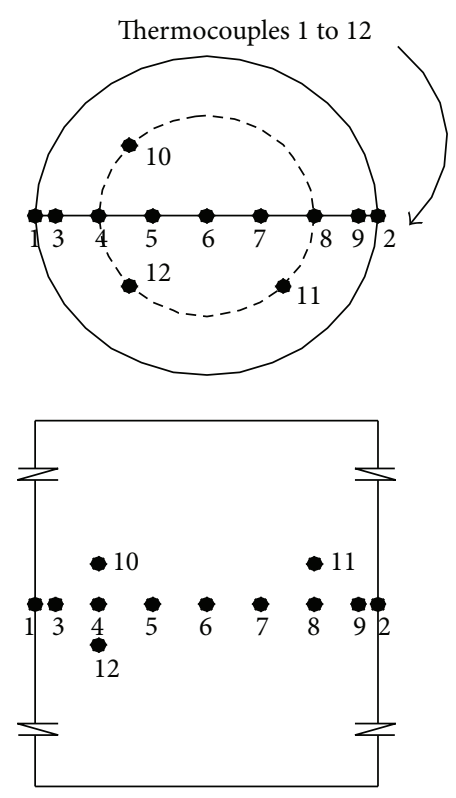

(b)

$\begin{array}{ll}\text { Numbers 3-4 } & 16 \mathrm{~mm} \\ \text { Numbers 5-6 } & 15 \mathrm{~mm} \\ \text { Numbers 7-8 } & 14 \mathrm{~mm} \\ \text { Numbers 9-2 } & 2.5 \mathrm{~mm}\end{array}$

FIGURE 1: Schematic of an experimental setup for transient heat transfer experiments: (a) packed bed arrangement and (b) thermocouple positions inside the stainless steel pipe as elevation and plan.

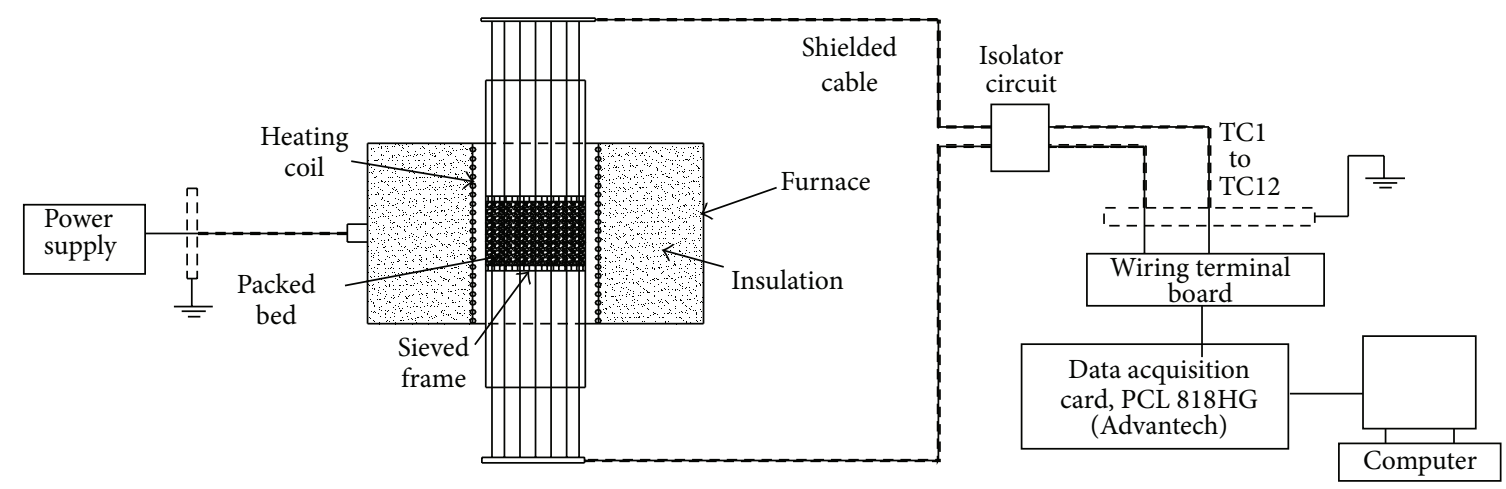

FIGURE 2: Schematic diagram of experimental setup and instrumentation for radial heat transfer measurements.

experiments is shown in Figure 2. Calibrated chromel-alumel $K$-type thermocouples of gauge $0.25 \mathrm{~mm}$ have been used for temperature measurement. The temperature measuring accuracy was $\pm 1 \mathrm{~K}$. The sheath of the shielded thermocouple wire is properly grounded. Data from the thermocouples are recorded continuously using a high-gain data acquisition card (PCL 818HG, Advantech, USA) and a personal computer. The maximum sampling rate of the card is $100 \mathrm{kS} / \mathrm{s}$. Thermocouples are connected to the data acquisition system card through isolation modules (ADAM 3011, Advantech, 


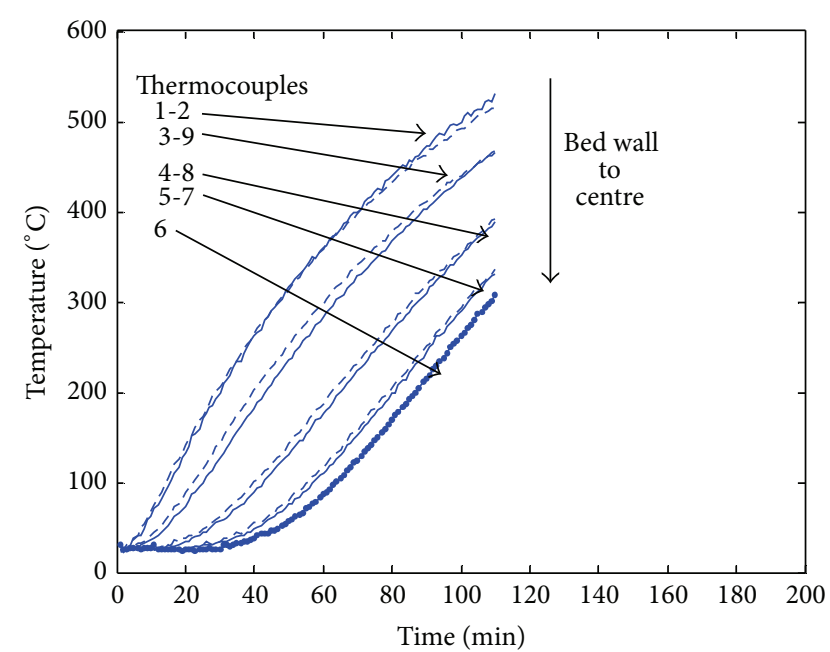

FIgURE 3: Temperature evolution in radial heat transfer experiments.

USA). The selected temperature range for the present work is $400 \mathrm{~K}$ to $900 \mathrm{~K}$.

\section{Analysis of the Experimental Data and Discussion}

The experiments were conducted in a vertical cylindrical bed kept inside a vertical 3-segment tubular furnace, heated so as to give a large constant temperature zone. The packed bed is contained in a stainless steel tube, and the measurements are made in the radial direction at a midway cross-section. Care is taken to ensure $1 \mathrm{D}$ heat transfer in the radial direction. Figure 3 depicts the typical temperature evolution obtained for the bed using thermocouples numbers 1 to 9 . Thermocouple 6 shows the lowest temperatures as it is at the centre of the bed.

Thermocouples numbers 1 and 2, 3 and 9, 4 and 8, and 5 and 7 are placed diametrically opposite to each other, distance from the center being almost the same; hence, their temperatures are similar. Thermocouples numbers 10 , 11 , and 12 are placed to verify that the heat flow is onedimensional. Thermocouples numbers 4,10 , and 12 are at the same distance of $18.5 \mathrm{~mm}$ from the wall but at different axial and azimuthal positions. Similarly thermocouples 11 and 8 are placed $17.5 \mathrm{~mm}$ from the wall but have different azimuth angles. It was observed that the variations in temperatures in the axial as well as the azimuthal directions were as low as $\pm 0.15 \%$. Figure 4 depicts the typical radial temperature distributions as time progresses.

Experimentally obtained temperatures are shown using the "*" symbol. The lines shown are best fit curves using a quadratic function. The present system is cylindrical in nature; considering the same, the authors also used Bessel function [34] of first and second kind to obtain a best fit. The variation in temperature obtained by quadratic function and Bessel function was observed to be $\pm 0.25 \%$. A schematic of the fitted curve is shown in Figures 5 and 6 for times $t$ and

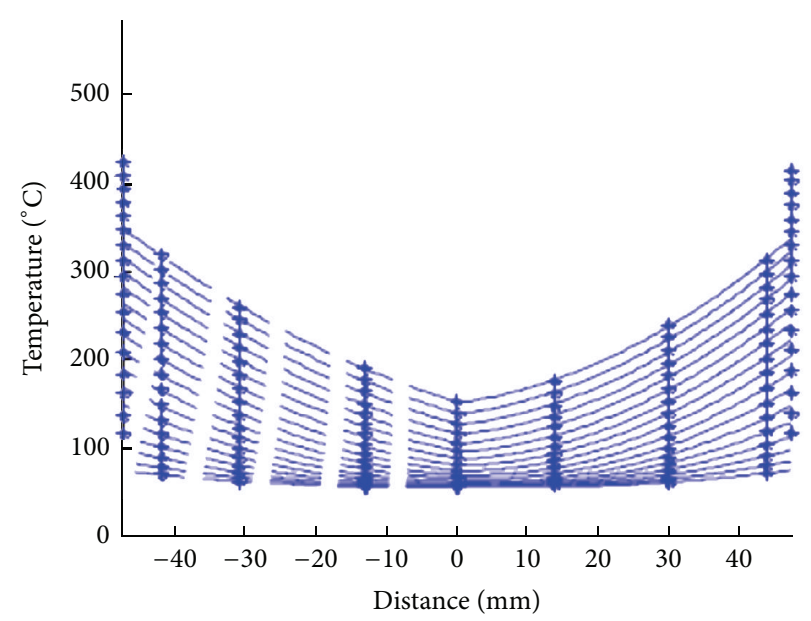

- $\quad$ Fitted TC 6-9

- - - Fitted TC 3-6

* $\quad$ Measured temperature

FIGURE 4: Radial temperature profiles at various times.

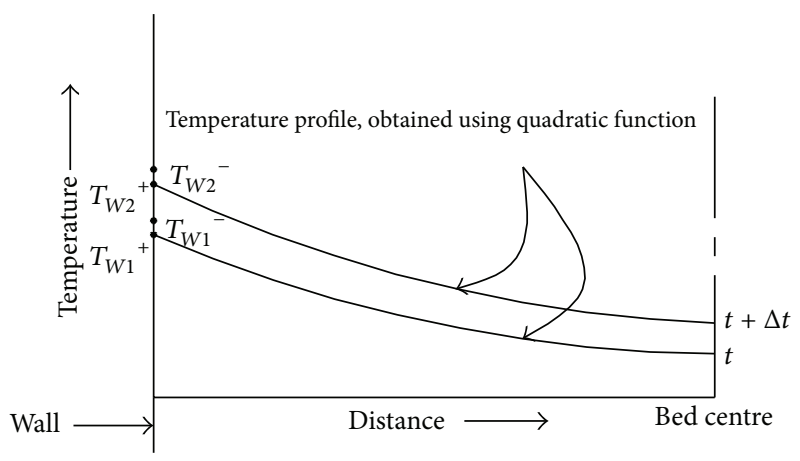

FIGURE 5: Schematic showing temperature profiles at times $t$ and $t+$ $\Delta t$ and the extrapolated wall temperatures.

$t+\Delta t$. The measured wall temperature is shown by $T_{w 1}{ }^{-}$and $T_{w 2}{ }^{-}$. The temperature at the wall obtained by extrapolation of the curves up to the wall is shown by $T_{w 1}{ }^{+}$and $T_{w 2}{ }^{+}$.

For the given system at unit length, heat content within the material at particular time $(t)$ is calculated by integration using the fitted temperature profile as

$$
Q_{t}=(\text { heat content })_{t}=\rho C p 2 \pi \int_{0}^{r} r T(r) d r .
$$

$T I$ is the best fit polynomial for temperature as a function of radius of a packed bed, $r$ is the radius of the packed bed under consideration, $C p$ is the specific heat of the material, $\rho$ is the bulk density of the bed, and $Q_{t}$ is the heat content within the material at time $t$.

Thermocouples 3 and 9 are placed near the wall with a distance of less than $4 \mathrm{~mm}$ from the wall. Achenbach [35] observed that porosity near the wall is higher than that in the bulk (away from the wall). In radial direction, the variation of porosity near the wall levels out at 4 particle diameters. In the present experiments, average particle size is $4.3 \mathrm{~mm}$. As thermocouples 3 and 9 are placed in the near wall region 


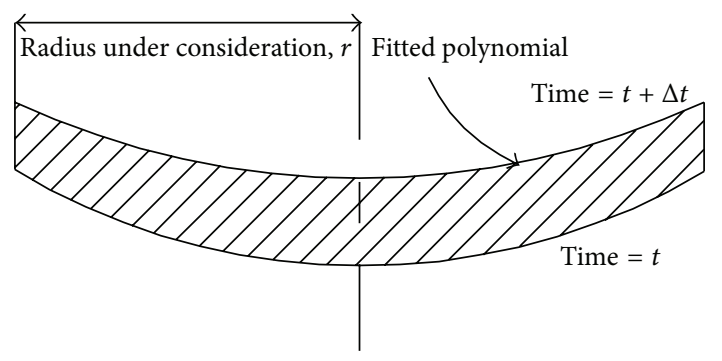

FIgURE 6: Best fit polynomial for bed temperature at times $t$ and $t+\Delta t$.

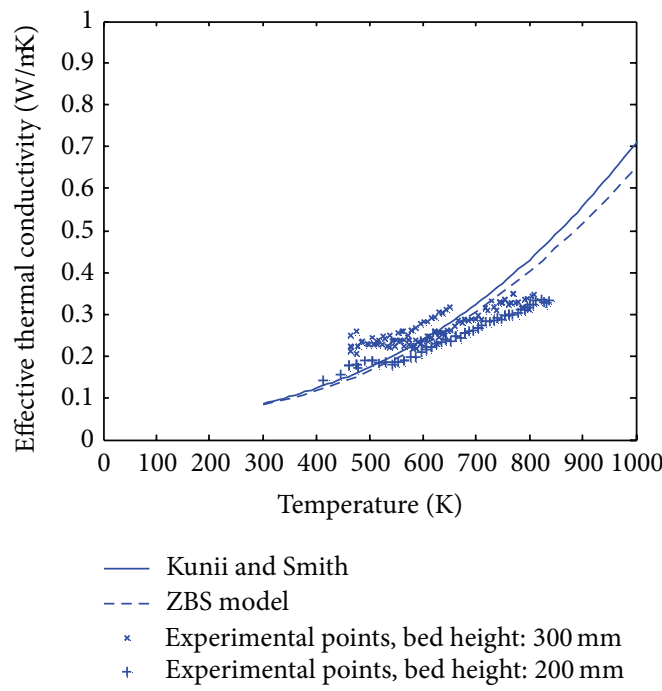

Figure 7: Comparison of measured $k_{e}$ values with models $[31,33]$.

wherein the porosity variation exists, they should not be included in calculation of effective thermal conductivity in bulk. It should be noted that thermocouples numbers 4 and 8 are placed at distance of $22 \mathrm{~mm}$ from the wall, which is more than five particle diameters.

Therefore, in order to determine the effective thermal conductivity in the bulk away from the wall region, the measured data of thermocouples $6,5,7,4$, and 8 were used. Rate of heat transferred to the bed under consideration, thus, was determined using (1), by fitting a quadratic using temperatures obtained from these thermocouples. Further, the temperature gradients $(\Delta T / \Delta r)$ at locations of thermocouples 4 and 8 were obtained from the fitted quadratic equation. Subsequently, the following equation is used to calculate the thermal conductivity in the bulk of the bed along with (1):

$$
q_{i}=\left(\frac{Q_{\Delta t+t}-Q_{t}}{\Delta t}\right)_{i}=2 \pi r_{i} k_{i}\left(\frac{\partial T}{\partial r}\right)_{i} .
$$

As discussed in previous section, Figure 7 represents the bed thermal conductivities measured with iron ore particles of average size $4.3 \mathrm{~mm}$ for bed heights of $300 \mathrm{~mm}$ and $200 \mathrm{~mm}$. Temperature measurements have been done at the bed heights of $150 \mathrm{~mm}$ and $100 \mathrm{~mm}$, respectively, below the top of the bed. The data presented correspond to several experiments conducted at varying heat input rates. Considering the variation one expects in packed bed experiments, reproducibility of the results is good. It is observed that effective thermal conductivity of the bed increases with temperature. Figure 7 depicts that the $k_{e}$ values obtained are in the range of $0.20-0.35 \mathrm{~W} / \mathrm{m} \cdot \mathrm{K}$. These values compare well with the values reported by several workers in the literature $[4,6,7,15,16,18,25,36]$. The data is obtained for the temperature range of 400 to $900 \mathrm{~K}$. The scatter obtained is more for the lower temperature compared to that at higher temperature. The scatter for the temperature range 400 to $600 \mathrm{~K}$ is 0.025 , for 600 to $700 \mathrm{~K}$ is 0.0234 , and for 700 to $900 \mathrm{~K}$ is 0.0164 . It is to be noted that the scatter in effective thermal conductivity is much higher than the error in $k_{e}$ values arising from error in measurement of temperature as well as thermocouple positions. The conductivity data obtained is compared with two models given by Kunii and Smith [31], Zehner and Schlunder [32], and Bauer and Schluender [33] as depicted in Figure 7.

The model presented by Zehner, Bauer, and Schlunder is popularly known as ZBS model. Both the models are presented as follows as a reference.

(1) Model proposed by Kunii and Smith

$$
\begin{aligned}
\frac{k_{e}^{0}}{k_{f}}= & \epsilon\left(1+\frac{h_{r v} D_{p}}{k_{f}}\right) \\
& +\frac{1-\epsilon}{\left(1 /\left(1 / \phi+h_{r s} D_{p} / k_{f}\right)+2 / 3\left(k_{f} / k_{s}\right)\right)},
\end{aligned}
$$

where

$$
\begin{aligned}
h_{r v}=4 & {\left[\frac{1}{(1+(\epsilon / 2(1-\epsilon))((1-\varepsilon) / \varepsilon))}\right] T^{3} } \\
h_{r s}=4 \sigma \frac{\varepsilon}{1-\varepsilon} T^{3} & \phi_{1}+\left(\phi_{1}-\phi_{2}\right) \frac{\epsilon-0.260}{0.216} \\
\phi_{1}= & 0.352\left(\frac{k_{s} / k_{f}-1}{k_{s} / k_{f}}\right)^{2} \\
& \cdot\left(\left\{\ln \left[\frac{k_{s}}{k_{f}}-0.545\left(\frac{k_{s}}{k_{f}}-1\right)\right]\right.\right. \\
& -\frac{2}{3 k_{s} / k_{f}} \\
\phi_{2}= & 0.072\left(\frac{k_{s} / k_{f}-1}{k_{s} / k_{f}}\right)^{2} \\
& \left.\cdot\left(\left\{\ln \left[\frac{k_{s}}{k_{f}}-0.925\left(\frac{k_{s}}{k_{s} / k_{f}}-1\right)\right\}\right)^{-1}\right)\right] \\
\left.\left.-0.075\left(\frac{k_{s} / k_{f}-1}{k_{s} / k_{f}}\right)\right\}\right)^{-1} & \frac{2}{3 k_{s} / k_{f}} .
\end{aligned}
$$


(2) ZBS model

$$
\begin{aligned}
\frac{k_{e}}{k_{f}}= & (1-\sqrt{1-\epsilon}) \\
& +\sqrt{1-\epsilon} \frac{2}{1-\left(k_{f} / k_{s}\right) B} \\
& \cdot\left[\frac{\left(1-k_{f} / k_{s}\right) B}{\left(1-\left(k_{f} / k_{s}\right) B\right)^{2}}\right. \\
& \left.\cdot \ln \frac{k_{s}}{k_{f} B}-\frac{B-1}{2}-\frac{B-1}{1-\left(k_{f} / k_{s}\right) B}\right] \\
+ & (1-\sqrt{1-\epsilon}) \frac{k_{r}}{k_{f}}+\sqrt{1-\epsilon}\left(\frac{k_{f}}{k_{r}}+\frac{k_{f}}{k_{s}}\right)^{-1},
\end{aligned}
$$

where

$$
\begin{gathered}
k_{r}=4 \sigma\left(\frac{\varepsilon}{2-\varepsilon}\right) T^{3} D_{p} \\
B=C\left(\frac{1-\epsilon}{\epsilon}\right)^{10 / 9} .
\end{gathered}
$$

Kunii and Smith developed an expression for effective thermal conductivity with stagnant fluid based on one-dimensional heat diffusion model for a unit cell of packed spheres. ZBS model considered the heat flux assuming parallel heat flux vectors as a unit cell. ZBS model also accounted for particle shape, radiation effect, fluid pressure dependence, contact conduction, particle flattening, shape and size distribution, and oxidation effects using adjustable parameters for particles. Particle shape factor is considered as 2.5. In the present study, the model is presented by omitting the surface oxide terms and low-pressure terms. Thermal conductivity of the single iron ore particle was measured and observed to be 0.95 to 2.8 for the temperature range of 300 to $1200 \mathrm{~K}$. For the same temperature range, emissivity was considered as 0.81 to 0.71 .

The $k_{e}$ values obtained in the present work were compared with those calculated using the reported models [3133]. They are depicted in Figure 7. It is interesting to note that the thermal conductivity values for packed beds of height $300 \mathrm{~mm}$ are higher than those for packed beds of $200 \mathrm{~mm}$ height. This can be attributed to the interparticle contact forces generated by the weight of bed. A detailed investigation on this aspect is being carried out and will be communicated in future.

\section{Conclusions}

A new experimental technique has been developed to measure the thermal conductivity of packed beds along the radial direction in a cylindrical packed bed. The technique involves heating a cylindrical packed bed from the periphery and measuring its transient response. The effective thermal conductivity values obtained were comparable to the values mentioned in the literature. The data obtained from experiments is comparable with ZBS model and the model by Kunii and Smith.

\section{Nomenclature}

B: Deformation coefficient

C: $\quad$ Particle shape factor

$D_{p}:$ Diameter of particle $(\mathrm{m})$

g: Acceleration due to gravity $\left(\mathrm{m} / \mathrm{s}^{2}\right)$

$h$ : Heat transfer coefficient $\left(\mathrm{W} / \mathrm{m}^{2} \cdot \mathrm{K}\right)$

$h_{r s}$ : Heat transfer coefficient of thermal radiation, solid surface to solid surface $\left(\mathrm{W} / \mathrm{m}^{2} \cdot \mathrm{K}\right)$

$h_{r v}$ : Heat transfer coefficient of thermal radiation, void space to void space $\left(\mathrm{W} / \mathrm{m}^{2} \cdot \mathrm{K}\right)$

$h_{w}$ : Heat transfer coefficient in packed bed with fluid flowing $\left(\mathrm{W} / \mathrm{m}^{2} \cdot \mathrm{K}\right)$

$k$ : $\quad$ Thermal conductivity of packed bed $(\mathrm{W} / \mathrm{m} \cdot \mathrm{K})$

$k_{e}$ : $\quad$ Effective thermal conductivity of packed bed $(\mathrm{W} / \mathrm{m} \cdot \mathrm{K})$

$k_{e}^{0}$ : $\quad$ Effective thermal conductivity of packed bed in motionless fluid $(\mathrm{W} / \mathrm{m} \cdot \mathrm{K})$

$k_{e w}$ : Effective thermal conductivity in the vicinity of the wall of packed bed $(\mathrm{W} / \mathrm{m} \cdot \mathrm{K})$

$k_{s s}$ : Thermal conductivity of stainless steel disk $(\mathrm{W} / \mathrm{m} \cdot \mathrm{K})$

$k_{e}$ : $\quad$ Effective thermal conductivity of packed bed $(\mathrm{W} / \mathrm{m} \cdot \mathrm{K})$

$k_{f}$ : Thermal conductivity of fluid $(\mathrm{W} / \mathrm{m} \cdot \mathrm{K})$

$k_{r}$ : Radiative component of effective thermal conductivity $(\mathrm{W} / \mathrm{m} \cdot \mathrm{K})$

$q$ : $\quad$ Rate of heat transfer per unit length (W/m)

$r$ : Radius of a packed bed ( $\mathrm{m}$ )

$T_{w}{ }^{-}$: Measured temperature on the face of the stainless steel disk $(\mathrm{K})$

$T_{w}{ }^{+}$: Bed temperature at the interface obtained by extrapolation $(\mathrm{K})$

$\phi$ : Measure of the effective thickness of the fluid film adjacent to the contact point between two solid particles

$\epsilon: \quad$ Void fraction

$\varepsilon$ : Emissivity

$\sigma: \quad$ Stefan-Boltzmann constant $\left(\mathrm{W} / \mathrm{m}^{2} \cdot \mathrm{K}^{-4}\right)$.

\section{Conflict of Interests}

The authors declare that there is no conflict of interests regarding the publication of this paper. 


\section{References}

[1] S. Yagi and D. Kunii, "Studies on effective thermal conductivities in packed beds," AIChE Journal, vol. 3, no. 3, pp. 373-381, 1957.

[2] B. Legawiec and D. Ziólkowski, "Structure, voidage and effective thermal conductivity of solids within near-wall region of beds packed with spherical pellets in tubes," Chemical Engineering Science, vol. 49, no. 15, pp. 2513-2520, 1994.

[3] S. Yagi and D. Kunii, "Studies on heat transfer near wall surface in packed beds," AIChE Journal, vol. 6, no. 1, pp. 97-104, 1960.

[4] S. Yagi and N. Wakao, "Heat and mass transfer from wall to fluid in packed beds," AIChE Journal, vol. 5, no. 1, pp. 79-85, 1959.

[5] W. E. Ranz, "Friction and heat transfer coefficients for single particles and packed beds," Chemical Engineering Progress, vol. 27, pp. 247-253, 1952.

[6] W. Schotte, "Thermal conductivity of packed beds", AIChE Journal, vol. 6, no. 1, pp. 63-67, 1960.

[7] K. Ofuchi and D. Kunii, "Heat-transfer characteristics of packed beds with stagnant fluids," International Journal of Heat and Mass Transfer, vol. 8, no. 5, pp. 749-757, 1965.

[8] W. G. Kannuluick and L. H. Martin, "Conduction of heat in powders," Proceedings of the Royal Society of London A, vol. 141, no. 843, pp. 144-158, 1933.

[9] A. Gemant, "The thermal conductivity of soils," Journal of Applied Physics, vol. 21, no. 8, pp. 750-752, 1950.

[10] E. W. Schumann and V. Voss, "Heat flow through granulated material," Fuel, vol. 13, pp. 249-256, 1934.

[11] J. Webb, "Thermal conductivity of soil," Nature, vol. 177, no. 4517, p. 989, 1956.

[12] S. Yagi, D. Kunii, and N. Wakao, "Radially effective thermal conductivities in packed beds," in International Development in Heat Transfer. Part IV, pp. 742-749, ASME, 1961.

[13] T. Koya and D. Kunii, "Measurement of thermal conductivities of solid particles in packed beds," International Journal of Chemical Engineering, vol. 12, no. 1, pp. 162-167, 1972.

[14] A. J. Slavin, F. A. Londry, and J. Harrison, "A new model for the effective thermal conductivity of packed beds of solid spheroids: alumina in helium between 100 and $500^{\circ} \mathrm{C}$," International Journal of Heat and Mass Transfer, vol. 43, no. 12, pp. 2059-2073, 2000.

[15] M. M. Melanson and A. G. Dixon, "Solid conduction in low $\mathrm{dt} / \mathrm{dp}$ beds of spheres, pellets and rings," International Journal of Heat and Mass Transfer, vol. 28, no. 2, pp. 383-394, 1985.

[16] G. P. Willhite, D. Kunii, and J. M. Smith, "Heat transfer in beds of fine particles (heat transfer perpendicular to flow)," AIChE Journal, vol. 8, no. 3, pp. 340-345, 1962.

[17] S. Yagi, D. Kunii, and N. Wakao, "Studies on axial effective thermal conductivities in packed beds," AIChE Journal, vol. 6, no. 4, pp. 543-546, 1960.

[18] K. Nasr, R. Viskanta, and S. Ramadhyani, "An experimental evaluation of the effective thermal conductivities of packed beds at high temperatures," Journal of Heat Transfer, vol. 116, no. 4, pp. 829-837, 1994.

[19] R. H. Wilhelm, W. C. Johnson, R. Wynkoop, and D. W. Collier, "Reaction rate, heat transfer and temperature distribution in fixed-bed catalytic converters," Chemical Engineering Progresss, vol. 44, pp. 105-115, 1948.

[20] G. S. G. Beveridge and D. P. Haughey, "Axial heat transfer in packed beds. Stagnant beds between 20 and $750^{\circ} \mathrm{C}$," International Journal of Heat and Mass Transfer, vol. 14, no. 8, pp. 1093$1113,1971$.
[21] D. R. Shonnard and S. Whitaker, "The effective thermal conductivity for a point-contact porous medium: an experimental study," International Journal of Heat and Mass Transfer, vol. 32, no. 3, pp. 503-512, 1989.

[22] A. Abou-Sena, A. Ying, and M. Abdou, "Experimental investigation and analysis of the effective thermal properties of beryllium packed beds," Fusion Science and Technology, vol. 44, no. 1, pp. 79-84, 2003.

[23] M. Pons and P. Dantzer, "Determination of thermal conductivity and wall heat transfer coefficient of hydrogen storage materials," International Journal of Hydrogen Energy, vol. 19, no. 7, pp. 611-616, 1994.

[24] H. T. Aichlmayr and F. A. Kulacki, "A transient technique for measuring the effective thermal conductivity of saturated porous media with a constant boundary heat flux," Journal of Heat Transfer, vol. 128, no. 11, pp. 1217-1220, 2006.

[25] E. Tsotsas and H. Martin, "Thermal conductivity of packed beds: a review," Chemical Engineering and Processing, vol. 22, no. 1, pp. 19-37, 1987.

[26] D. L. Swift, "The thermal conductivity of spherical metal powders including the effect of an oxide coating," International Journal of Heat and Mass Transfer, vol. 9, no. 10, pp. 1061-1074, 1966.

[27] S. Masamune and J. M. Smith, "Thermal conductivity of beds of spherical particles," Industrial \& Engineering Chemistry Fundamentals, vol. 2, no. 2, pp. 136-143, 1963.

[28] M. A. Durán and B. S. White, "Bayesian estimation applied to effective heat transfer coefficients in a packed bed," Chemical Engineering Science, vol. 50, no. 3, pp. 495-510, 1995.

[29] A. D. Caldwell, "Wall heat transfer coefficients with gas flow through packed beds," Chemical Engineering Science, vol. 23, no. 4, pp. 393-395, 1968.

[30] W. D. Kingery and M. C. Mcquarrie, "Thermal conductivity. I: concepts of measurement and factors affecting thermal conductivity of ceramic materials," Journal of the American Ceramic Society, vol. 37, no. 2, pp. 67-72, 1954.

[31] D. Kunii and J. M. Smith, "Heat transfer characteristics of porous rocks," The American Institute of Chemical Engineers Journal, vol. 6, pp. 71-79, 1960.

[32] P. Zehner and E. U. Schlunder, "Thermal conductivity of granular materials at moderate temperature," Chemie-IngenieurTechnik, vol. 42, no. 14, pp. 933-941, 1970 (German).

[33] R. Bauer and E. U. Schluender, "Effective radial thermal conductivity of packings in gas flow. Part I. Convective transport coefficient," International Journal of Chemical Engineering, vol. 18, no. 2, pp. 181-188, 1978.

[34] F. Incropera and D. DeWitt, Introduction to Heat Transfer, Wiley, 2006.

[35] E. Achenbach, "Heat and flow characteristics of packed beds," Experimental Thermal and Fluid Science, vol. 10, no. 1, pp. 17-27, 1995.

[36] W. Woodside and J. H. Messmer, "Thermal conductivity of porous media. I. Unconsolidated sands," Journal of Applied Physics, vol. 32, no. 9, pp. 1688-1699, 1961. 

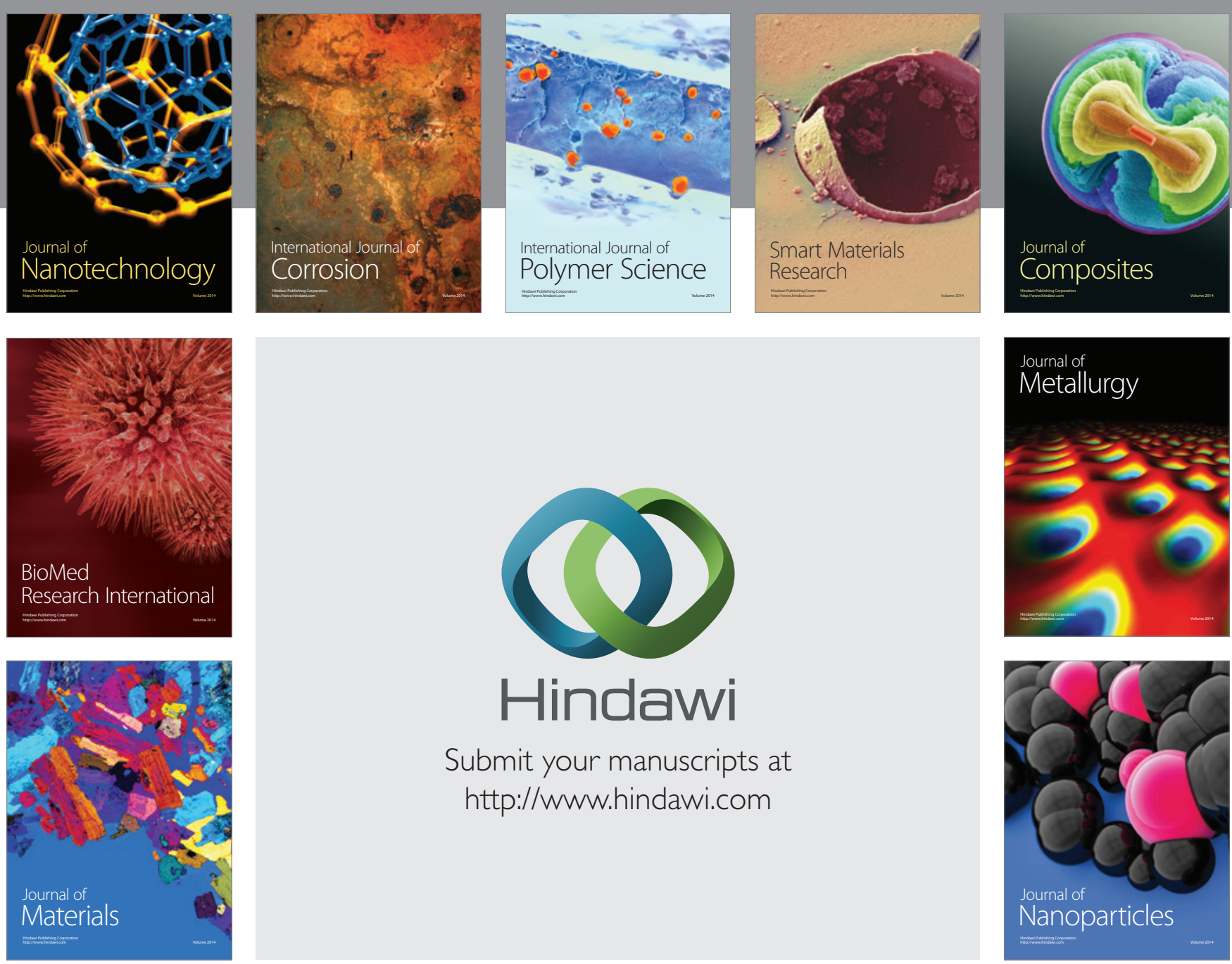

Submit your manuscripts at http://www.hindawi.com
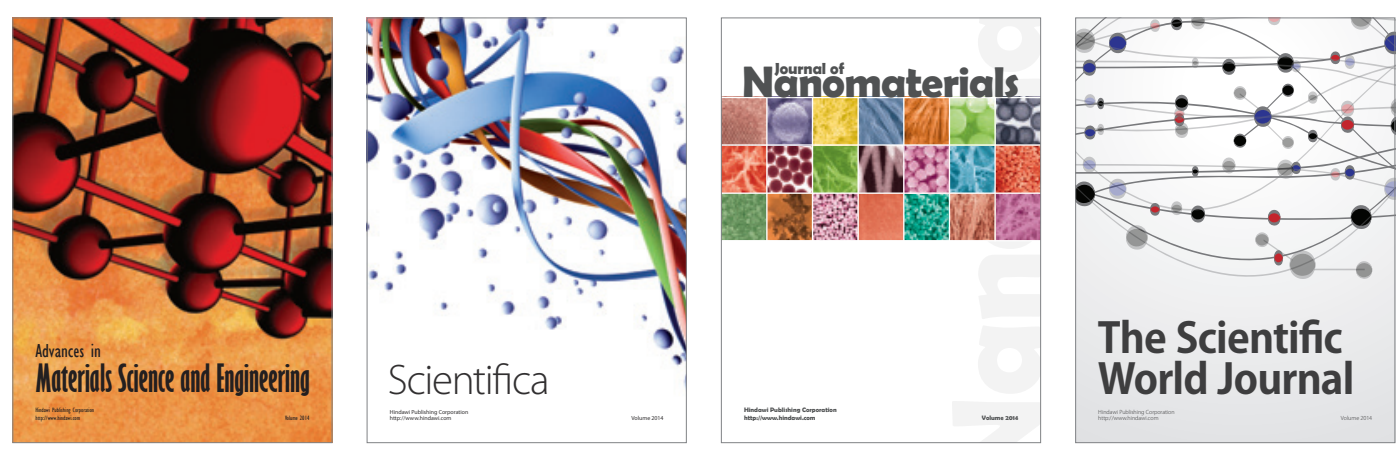

\section{The Scientific World Journal}
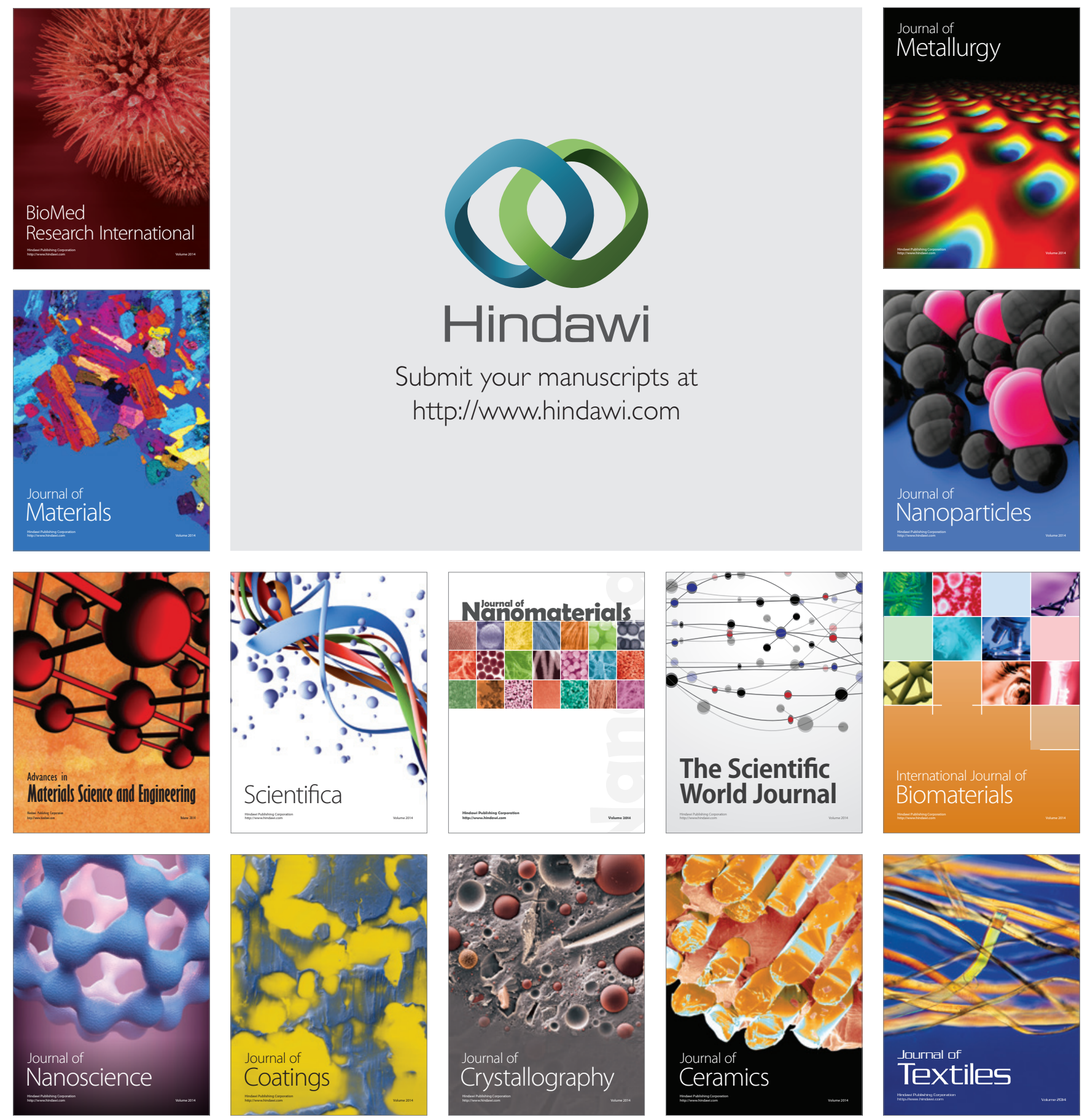